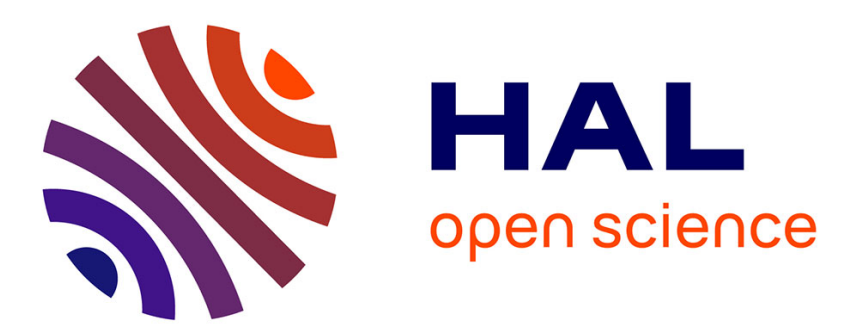

\title{
Découverte des bactéries phytopathogènes, il y a cent ans : controverses et polémiques transatlantiques
}

\author{
Jean-Pierre Paulin
}

\section{To cite this version:}

Jean-Pierre Paulin. Découverte des bactéries phytopathogènes, il y a cent ans: controverses et polémiques transatlantiques. Journée commune Académie des sciences \& Académie d'agriculture de France, Académie des Sciences. FRA., Feb 2001, Paris, France. 2 p. hal-01600244

\section{HAL Id: hal-01600244 \\ https://hal.science/hal-01600244}

Submitted on 7 Jun 2020

HAL is a multi-disciplinary open access archive for the deposit and dissemination of scientific research documents, whether they are published or not. The documents may come from teaching and research institutions in France or abroad, or from public or private research centers.
L'archive ouverte pluridisciplinaire HAL, est destinée au dépôt et à la diffusion de documents scientifiques de niveau recherche, publiés ou non, émanant des établissements d'enseignement et de recherche français ou étrangers, des laboratoires publics ou privés.

\section{다(1)(2)}

Distributed under a Creative Commons Attribution - ShareAlikel 4.0 International 


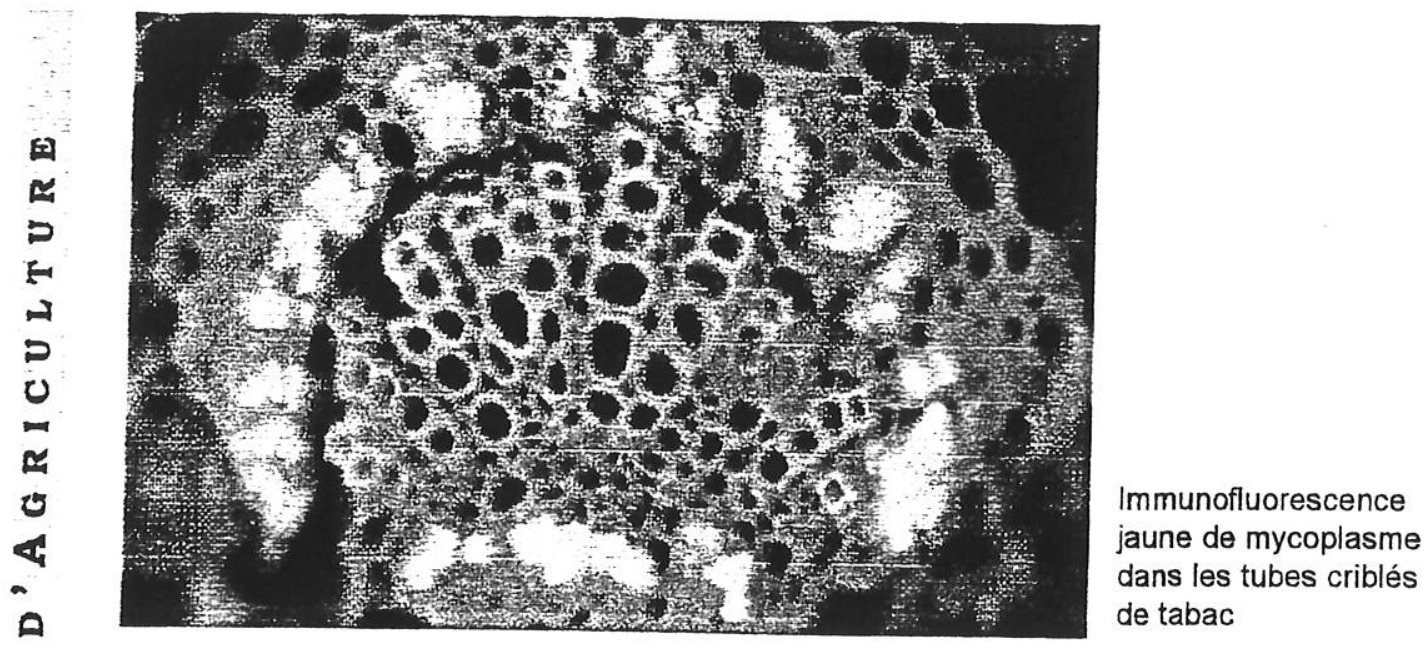

\section{AGENTS PATHOGENES DES PLANTES: DECOUVERTE,} PATHOGENIE, PROBLEMES DE SOCIËTÉ

Séance publique du Lundi 5 février de 10 h0o à $17 \mathrm{~h} 30$ - 2001

Coordonnateurs Joseph Bovt, Membre de l'Académie d'Agriculture de France, Correspondant de l'Académie des sciences et Michel TheluIR, Membre de l'Académie d'Agriculture de France, Membre de l'Académie des sciences.

\section{$10 \mathrm{~h}-12 \mathrm{~h} 30$ \\ Introduction}

Emergence de la notion d'agents pathogènes infectieux et leur importance en agriculture. Joseph Bové, Correspondant de l'Académie des sciences, Membre de l'Académie d'agriculture de France.

\section{Champignons}

Champignons des plantes: premiers agents reconnus pathogènes dans l'histoire des sciences. Frantz Rapilly, Membre de l'Académie d'agriculture de France.

Plantes et agents pathogènes, une liaison raffinée et dangereuse: l'exemple des champignons. Marie-Thérèse Esquerré-Tugaye, Correspondant de l'Académie d'agriculture de France.

\section{Bactéries}

Découverte des bactéries phytopathogènes, il y a cent ans: controverse et polémique transatlantiques. Jean-Pierre Paulin, Directeur de recherche INRA, Angers.

Dialogue moléculaire entre la plante et l'agent pathogène: l'exemple des bactéries. Christian Boucher, Directeur de recherche INRA, Toulouse.

\section{Mycoplasmes}

Mycoplasmes/Plantes/Insectes vecteurs : un ménage à trois! Monique Garnier, Directeur de recherche INRA, Bordeaux.

$$
\begin{gathered}
15 \mathrm{~h}-17 \mathrm{~h} 30 \\
\text { Virus }
\end{gathered}
$$

Découverte du premier virus, le virus de la mosä̈que du tabac: 1892 ou 1898 ? Hervé Lecoq, Directeur de recherche INRA, Avignon.

Les virus des plantes et la découverte récente de mécanismes fondamentaux insoupçonnés. Thierry Candresse, Directeur de recherche INRA, Bordeaux.

\section{(6)}

世

2

$\underline{\sim}$

b

\section{Viroüdes}

Un RNA nu, spécifique de plante et dix fois plus petit que le plus petit RNA de virus : viroüde. Ricardo Flores, Professeur, Université Polytechnique, Valence, Espagne.

\section{Conclusions}

Les plantes savent-elles se défendre? Bernard Fritig, Directeur de recherche CNRS, Strasbourg. 


\title{
DECOUVERTE DES BACTERIES PHYTOPATHOGENES IL Y A CENT ANS : CONTROVERSES ET POLEMIQUES TRANSATLANTIQUES
}

\author{
Jean-Pierre PAULIN*, Michel RIDE*, Jean-Pierre PRUNIER** \\ UMR INRA-INH-Université Angers, Centre INRA d'Angers \\ 42 rue Georges Morel, B.P. 57, 49071 BEAUCOUZE
}

La première bactériose des plantes établie de façon incontestable, c'est-à-dire dont la description satisfasse aux différentes étapes du "postulat" de $\mathrm{KOCH}$, a été décrite quelques années seulement après que ces étapes aient été établies, dans l'étude de l'étiologie de la tuberculose (Mycobacterium tuberculosis) (KOCH, 1882). Il s'agit d'une maladie grave des Pomoïdeae fruitières et ornementales (Pommier, Poirier, Aubépine), due à une entérobactérie, actuellement dénommée Erwinia amylovora, publiée par ARTHUR (1886). La découverte de maladies bactériennes des plantes n'a donc aucun aspect révolutionnaire : il est surprenant qu'elle ait été suivie par une vive controverse, qui a opposé le défenseur des bactérioses des végétaux, un américain, E.F. SMITH, à un professeur de botanique allemand, A. FISCHER, son détracteur. Celui-ci affirme, comme la plupart des phytopathologistes de l'époque, principalement en Europe, que les bactéries présentes dans les lésions observées sur les végétaux sont des agents de surinfection, l'origine première de la maladie étant toujours un champignon. Les justifications de cette affirmation sont simples : i) les bactéries ne possèdent aucun moyen pour pénétrer dans les cellules végétales; ii) si elles sont entraînées dans les tissus à l'occasion de blessures, les barrières de défenses naturelles de la plante préviennent sa progression; iii) l'apoplaste dans lequel peuvent se trouver placées d'éventuelles bactéries est un milieu dépourvu d'éléments nutritifs qui ne permet pas la multiplication bactérienne. La réponse de E.F. SMITH est développée en des dizaines de pages de plusieurs articles (en allemand). Elle peut se résumer ainsi : il est aisé de vérifier expérimentalement dans le cas des bactérioses des plantes toutes les phases du "postulat" de KOCH depuis l'isolement de l'agent responsable, la culture pure, jusqu'au réisolement après inoculation et obtention des symptômes. Cette preuve expérimentale, il l'a apportée lui-même, où il la trouve décrite par des collègues, dans près de 10 cas différents de maladies, décrites au début du siècle. Le ton très vif des échanges, et le fait qu'ils oppossent un professeur émérite d'une vieille Université allemande (Leipzig) à un pathologiste de "terrain" du "Ministère de l'Agriculture" (USDA) des Etats-Unis, a sans doute contribué à donner un certain relief à cette dispute, qui est parfois considérée comme emblématique d'une rivalité scientifique entre l'Ancien et le Nouveau Monde à la fin du 19ème siècle. En fait, elle apporte peu sur le plan scientifique ou technique, sinon qu'elle confirme l'importance de l'expérimentation dans l'établissement de certaines vérités scientifiques. A la fin de ces échanges (1901) il n'y aura plus de contestation sur l'existence des bactérioses des plantes ; par ailleurs, E.F. SMITH, et la phytopathologie américaine, prennent une place incontestée de pionniers en phytobactériologie. 
De la dizaine de bactéries phytopathogènes connues au début du siècle, on est passé actuellement à environ 350 espèces et pathovars, appartenant à 21 genres différents. La taxonomie des bactéries phytopathogènes, après une certaine insularité, qui confinait l'ensemble des bactéries responsables de maladies dans une seule tribu (Erwiniae) renfermant deux genres (Erwinia et Phytomonas), est maintenant complètement fondue avec la taxonomie bactérienne en général. Il s'en suit une nomenclature internationalement reconnue, et qui n'est pas particulière au domaine de la phytopathologie. Une exception sur ce point est constituée par le pathovar, utilisé pour décrire un groupe de germes, au niveau infra-spécifique, qui se caractérisent par un comportement pathogène particulier (qui provoque une maladie donnée sur un hôte spécifique). On peut placer les bactéries phytopathogènes dans trois groupes, en fonction du type de symptômes qu'elles provoquent sur la plante : les nécrogènes (nécrose, flétrissement), les macergènes (pourriture), les oncogènes (tumeurs, hyperplasie). A ces types de manifestations sont associés différents modes dominants d'interactions entre la bactérie et l'hôte, pour conduire au développement de la maladie. Ces interactions sont très généralement établies à partir de l'apoplasme, bien que certaines bactéries ne soient présentes que dans les tissus conducteurs (xylèmes et phloèmes). Elles peuvent mettre en jeu un système de sécrétion des protéines (système III) particulier aux bactéries pathogènes (de l'homme et de l'animal, du végétal), des toxines, des enzymes hydrolytiques (pectinases, cellulases), des phytohormones. Les bactéries du genre Agrobacterium, elles, modifient la physiologie de la plante par transfert de gènes à partir d'un plasmide dans le génome de l'hôte. Aucune bactérie phytopathogène n'a le pouvoir d'atteindre par elle-même son site d'infection. Les bactéries de l'apoplaste doivent y être entrainées à l'occasion de blessures, ou au travers d'ouvertures naturelles de la plante. Les bactéries des tissus conducteurs y sont introduites par des insectes vecteurs. Une des conséquences de ces caractères particuliers est que les épidémies provoquées par les bactéries sont très dépendantes de facteurs climatiques, et souvent d'expression très irrégulière. Néanmoins, certaines bactérioses ont une importance économique majeure, étant des facteurs limitant de la production de certains végétaux (Ralstonia solanacearum/Solanées, Xanthomonas oryzae/Riz), dans plusieurs régions du monde. Ce sont également parfois des agents pathogènes de "quarantaine" dont l'existence limite les échanges internationaux (Xanthomonas axonopodis pv. citri, Erwinia amylovora) ou de "qualité", dont l'action déprécie la valeur marchande des produits (Pseudomonas syringae pv. tomato, Xanthomonas a. pv. vesicatoria). Elles justifient donc des mesures de lutte, souvent coûteuses, mais imparfaites. Celles-ci reposent surtout sur la prophylaxie, associée à des traitements chimiques (métaux lourds, antibiotiques) et à l'emploi de variétés résistantes, lorsqu'elles sont disponibles. 